\title{
Numerical Investigation of a Jet-Stabilized Combustion System Operated with Low-Calorific SOFC Off-Gas
}

\author{
T. Lingstädt*, A.M. Drude ${ }^{\dagger}$, F. Grimm ${ }^{\ddagger}$, P. Kutne ${ }^{\S}$, and M. Aigner ${ }^{\llbracket}$ \\ Institute of Combustion Technology \\ German Aerospace Center (DLR) \\ Pfaffenwaldring 38-40, 70569 Stuttgart, Germany
}

\begin{abstract}
An increasing importance of decentralized energy production based on renewable resources in combination with rising power demands requires relatively small energy conversion systems in terms of power output. This situation is addressed at the German Aerospace Center with the development of a hybrid power plant demonstrator with a high temperature fuel cell. The power plant requires burner concepts for low calorific gases capable of combusting the exhaust products of the fuel cell anode side, here referred to as SOFC (solid oxide fuel cell) off-gas.

The combustor behavior for the demonstrator plant is investigated in this work by means of numerical simulations and basic experiments. As a main focus, simulations are employed in order to characterize the combustion system in greater detail. Several full- and part-load conditions are treated with steady state reacting RANS (Reynolds Averaged Navier Stokes) simulations. The numerical investigations are validated with averaged flame images from $\mathrm{OH}^{*}$-chemiluminescence data. Based on this, a detailed insight into flow field and combustion characteristics is provided. It is shown that the employed CFD modeling strategy, accounting for turbulence, detailed combustion kinetics, and heat loss effects can be used as a reliable design and diagnostics tool, capturing flow field and combustion accurately with at the same time very low overall computational costs.
\end{abstract}

$\begin{array}{lll} & & \text { Abbreviations } \\ \text { DLR } & =\text { German Aerospace Center } \\ \text { FLOX } & =\text { Flameless Oxidation } \\ \text { LHV } & =\text { Lower Heating Value } \\ \text { MGT } & =\text { Micro Gas Turbine } \\ \text { MILD } & =\text { Moderate or Intense Low-Oxygen Dilution Combustion } \\ \text { NG } & =\text { Natural Gas } \\ \text { SOFC } & =\text { Solid Oxide Fuel Cell }\end{array}$

\section{Introduction}

Conventional fossil fuels are a highly demanded but at the same time limited energy source. As a matter of fact, global electrical energy needs to increase rapidly. Thus, it is important to develop power plant concepts with high efficiency. One promising concept is the SOFC/MGT (micro gas turbine) hybrid power plant, as currently being developed and built as a demonstrator at German Aerospace Center (DLR) in a collaboration of the Institute of Combustion Technology (VT) and the Institute of Engineering Thermodynamics (TT) [1]. Hybrid power plants not only provide a large potential for efficiency increase but also for emissions reduction and operational flexibility.

On the experimental side, a solid oxide fuel cell emulator is integrated into a standard micro gas turbine cycle between compressor and turbine, as shown in Fig. 1. An atmospheric test rig was used to experimentally characterize

\footnotetext{
*Research Engineer, Institute of Combustion Technology, German Aerospace Center (DLR), Stuttgart, Germany, timo.lingstaedt@ dlr.de

${ }^{\dagger}$ Research Assistant, Institute of Combustion Technology, German Aerospace Center (DLR), Stuttgart, Germany

${ }^{\ddagger}$ Research Engineer, Institute of Combustion Technology, German Aerospace Center (DLR), Stuttgart, Germany

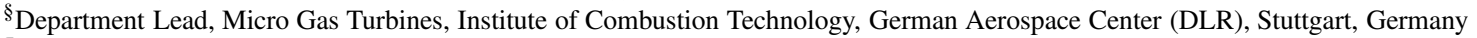

"I Head of Institute, Institute of Combustion Technology, German Aerospace Center (DLR), Stuttgart, Germany
} 


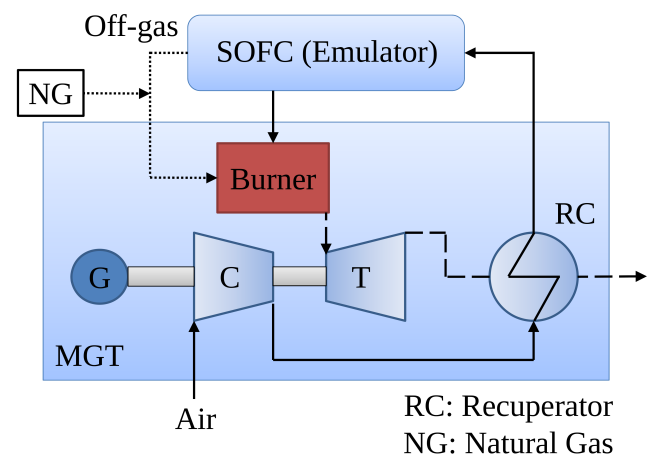

Fig. 1 Conceptual drawing of the DLR Hybrid Power Plant System with SOFC off-gas emulation.

the burner towards its final purpose of running in the power plant under very low-caloric, hybrid conditions. Those are provided as operational boundary conditions from the overall power plant specifications via numerical cycle simulations. The investigated burner is coupled with an SOFC emulator [2] in order to simulate the thermodynamic and fluid dynamic properties of an actual fuel cell. An additional natural gas supply was used for stability reasons in part-load operation with the low caloric off-gas. As mentioned previously, one of the key features of the power plant demonstrator is operational flexibility. Therefore, the developed burner has to provide a wide operational range, including SOFC off-gas and standard micro gas turbine operation. As pointed out by [2], existing SOFC applications employ catalytic or conventional diffusion combustion systems [3-5], which are not particularly suited for attached turbine processes. In the present work, a partially premixed, jet-stabilized FLOX®-similar combustor is used.

The FLOX $囚$ concept was originally designed as volumetric or MILD combustion for the use in industrial furnaces [6, 7]. In the latest MGT combustion systems however, the jet-stabilized combustion features mainly discrete flames rather than volumetric combustion, which is only achieved under very lean part load conditions. Fuel is injected coaxially in the main flow direction in order to partially premix air and fuel in an upstream mixing section before entering the combustion chamber. Due to the rather high jet velocities, a strong inner recirculation zone is present, where hot gases consisting of combustion products are transported back to the reaction zone. The results are a relatively homogeneous temperature distribution, a wide and stable operation range, and low emissions [8, 9]. Furthermore, the flame flashback risk is reduced due to the high jet velocities, even for fuel with large flame speeds such as hydrogen [10, 11]. As summarised by [2], such jet-flame based FLOX®systems were extended with swirl-stabilized pilot stage burners, in order to further extend the burner operation range [12-14]. However, no pilot staging is used in the presented burner system.

In this work, a jet-stabilized, low-calorific combustor is investigated numerically and with basic experiments. Steady state reacting RANS (Reynolds Averaged Navier Stokes) simulations are carried out. Results are validated with experimental data from $\mathrm{OH}^{*}$-chemiluminescence for mean reaction zone shape and flame lift-off height. Subsequently, conclusions on flow field and temperature distribution in the combustion chamber are drawn. The numerical model incorporates turbulence modeling, detailed combustion schemes and heat loss effects, which have to be taken into consideration in low-calorific applications as in the present case. With the establishment of a detailed model that runs at the same time at very low computational costs, operation conditions that are not viewed in experiments can still be reliably predicted and investigated. Additionally, the numerical simulations can add valid information of flow field and temperature to the experimental data set.

The paper is structured as follows. At first, the investigated burner system is introduced. The operational range of the burner system, defined in order to suffice operational flexibility in the context of hybrid power plant application is explained. Consecutively, measurement techniques and the numerical methods and models are introduced. It is explained in detail how heat flux is modeled and therefore how heat loss effects are taken into consideration. Then, numerical and experimental results are shown, where the numerical model is validated with experimental data. Finally, numerical results are used in order to explain flow field and combustion in this particular application case. 


\section{SOFC Off-gas Burner}

The combustor investigated in this work is based on a twelve nozzle FLOX $₫$ concept [2] designed with regard to low total pressure loss while still providing high flexibility and stability. The test rig consists of a controlled electrical air heating device providing the relatively high combustor inlet temperatures for the hybrid power plant application. Additionally the possibility to add N2 to the air is given, taking into account the reduced O2-content of the fuel cell cathode exhaust used as "air" in this case. A so called super-heated steam generator, a device specifically developed to provide the required gas composition modeling the SOFC off-gas at a high temperature level, is connected as fuel supply to the test rig. This component is based on a hydrogen combustion chamber running under fuel rich conditions equipped with the possibility to mix-in the appropriate amounts of $\mathrm{CO}$ and $\mathrm{CO}$. The test rig is optically accessible. The integrated $\mathrm{OH}^{*}$-chemiluminescence signal and exhaust gas analysis are used for evaluation of the burner behavior. Since an important adjustment to the system design for the demonstrator system has been made, the operating conditions for the combustion chamber have changed significantly since preceding investigations carried out in [2]. A remarkable decrease of the resulting LHVs (lower heating values) in the off-gas over the complete operational range of the power plant has demanded a new investigation compared to [2], especially of the critical part load operating point and has led to new challenges guaranteeing a stable combustion over the whole operational range. This investigation has been covered and demonstrated by [15]. The studies in the presented work are based on those new combustor boundary conditions.

\section{A. Burner Setup}

The combustion system is shown in Fig. 2 It has been tested on an atmospheric test rig with optical access through quartz glass windows. Its official label is the DLR burner F20OG.01, where "F" stands for FLOX®-similar, jet stabilized combustion. "20" denotes the approximated power output class and "OG" means operation with Off-Gas from the fuel cell. The following version number indicates different development stages.

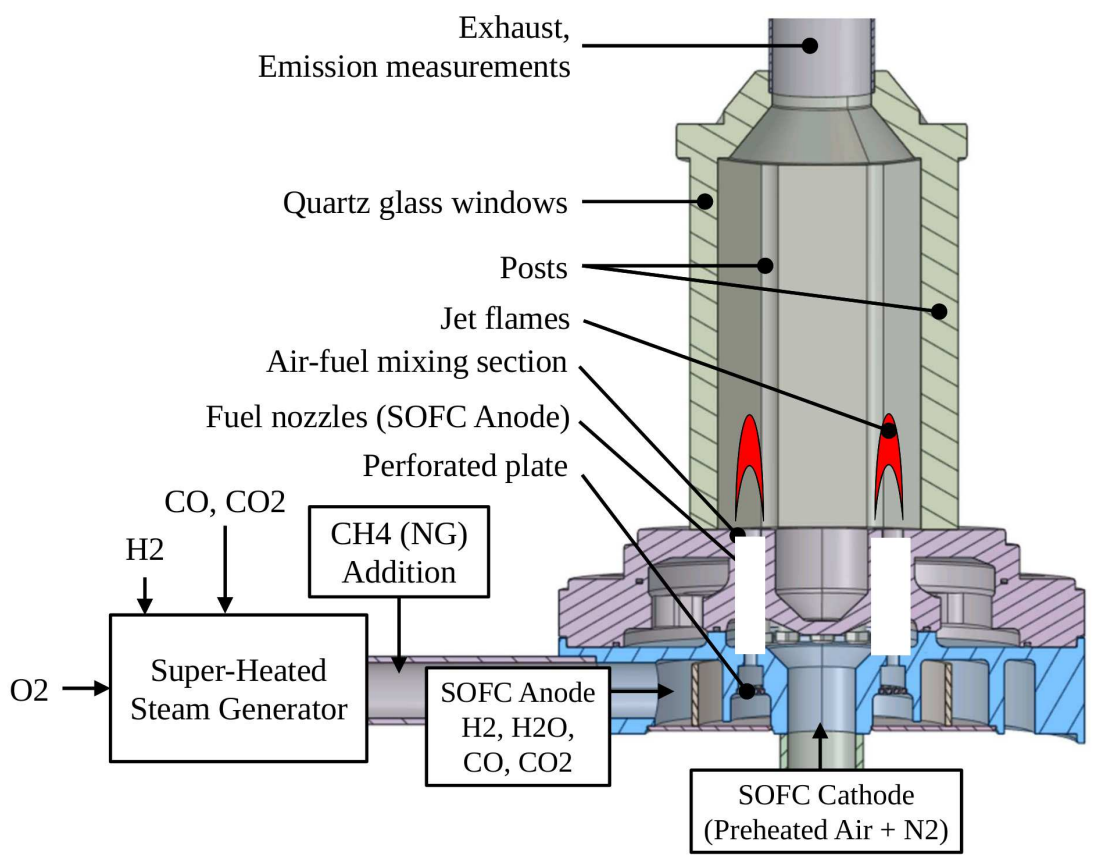

Fig. 2 Drawing of the SOFC off-gas burner designed for low-calorific combustion with inlet boundary conditions.

As introduced previously, the SOFC is not explicitly used for atmospheric tests, but an upstream heated steam generator, which is essentially a burner that realizes the necessary anode temperatures and compositions, as they would be produced by a fuel cell. This steam generator is designed to be able to realize a large range of operating conditions, as given by the overall hybrid power plant operation range. The steam generator is divided into a combustion chamber with rich $\mathrm{H} 2 / \mathrm{O} 2$ conditions to provide the necessary $\mathrm{H} 2$ and $\mathrm{H} 2 \mathrm{O}$ content in the exhaust gas and a downstream section, 
where $\mathrm{CO}$ and $\mathrm{CO} 2$ are injected. In case of part load conditions, natural gas is added to the steam generator exhaust gas, in order to provide stable combustion in case of part load conditions, which is challenging in this particular application with very low fuel heating values.

The anode gas is then redirected and led through a perforated plate, before it enters the combustion chamber through twelve circumferentially aligned fuel nozzles. The cathode is represented by a mixture of preheated air and added $\mathrm{N} 2$ that is injected centrally and distributed equally by an upstream plenum to reach the premixing zone around the twelve fuel nozzles in order to realize a partially premixed regime in co-flow alignment. After a short premixing zone, the partially premixed gas issues into the combustion chamber, where off-lifted jet flames form the reaction zone. Combustion products then leave the combustion chamber through an exhaust duct, where exhaust gas measurements were carried out.

\section{B. Operational Range}

In previous works [15], the investigated burner system was characterized experimentally. There, an operation range of the combustor was defined by low-dimensional system simulations in view of operation of the combustion system in the context of a hybrid power plant with upstream SOFC (solid oxide fuel cell). The theoretically obtained operation range is depicted in Fig. 3, together with points investigated in the preceding work [15].

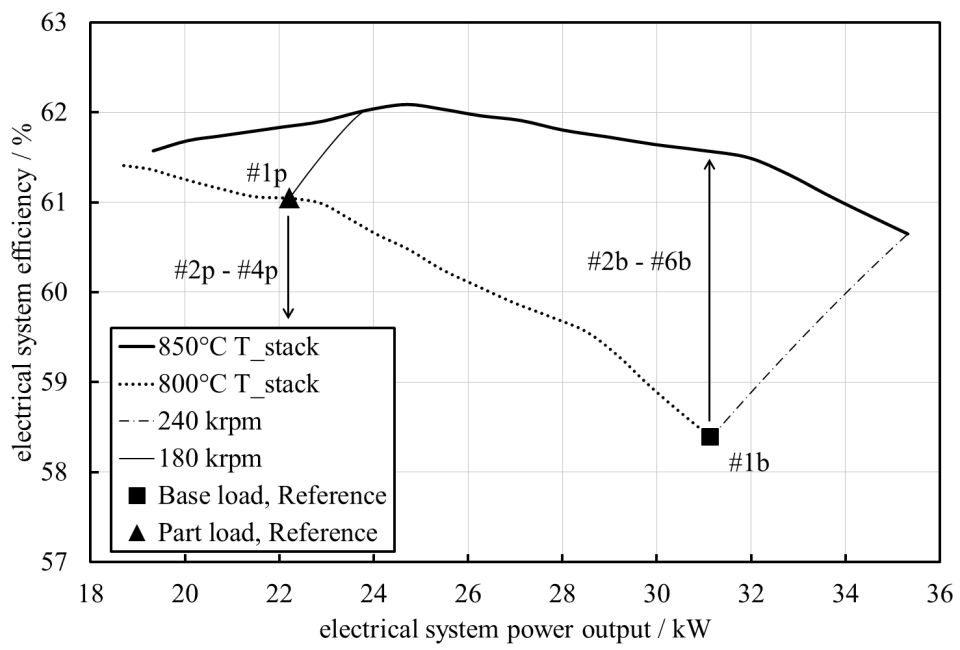

Fig. 3 Operational window of the SOFC Off-gas burner in the framework of the DLR hybrid power plant as a function of electrical system output over electrical system efficiency. Base-load and reference point \#1b and part-load reference point \#1p. Variations \#2b-\#6b denote a variation of fuel cell stack temperature and variations \#2p-\#4p mean variation of natural gas addition.

In Fig. [3] the operational window of the combustion system is limited by the stack temperature range of the fuel cell, indicated with the continuous and the dotted line in the graph of electrical system power output over electrical efficiency. The operational window is furthermore limited by full or base load operation at 240,000 revolutions per minute.

A base-load case is defined at full rotational shaft speed and a part-load case at approximately $70 \%$ of the system power output. In the current work, for the base-load and part-load regime, three cases are investigated, respectively. They are chosen with respect to pollutant emission, as shown in Fig. 4h as well as with respect to operation in a leaner, an optimum and a richer combustion regime, whereas all investigated points are in the overall lean combustion regime.

In Fig. 4b, global air fuel equivalence ratios of the different operation conditions are displayed. They are similar for base-load and part-load operation. The investigation in this paper therefore focuses on air fuel ratios in the range of about $\lambda \in[1.2 ; 3.6]$, being in the partially premixed, lean combustion regime.

As mentioned previously, the burner system is designed for Off-gas combustion. This means, that the fuel has very limited energy content, which is reflected by the depiction of adiabatic flame temperatures and temperature deltas over the combustion process, as shown in Fig. 47. Temperature deltas over the combustion process are estimated from Cantera simulations. Adiabatic flame temperatures are in the range of $T_{a d} \in[1500 \mathrm{~K} ; 1700 \mathrm{~K}]$, which is comparably 

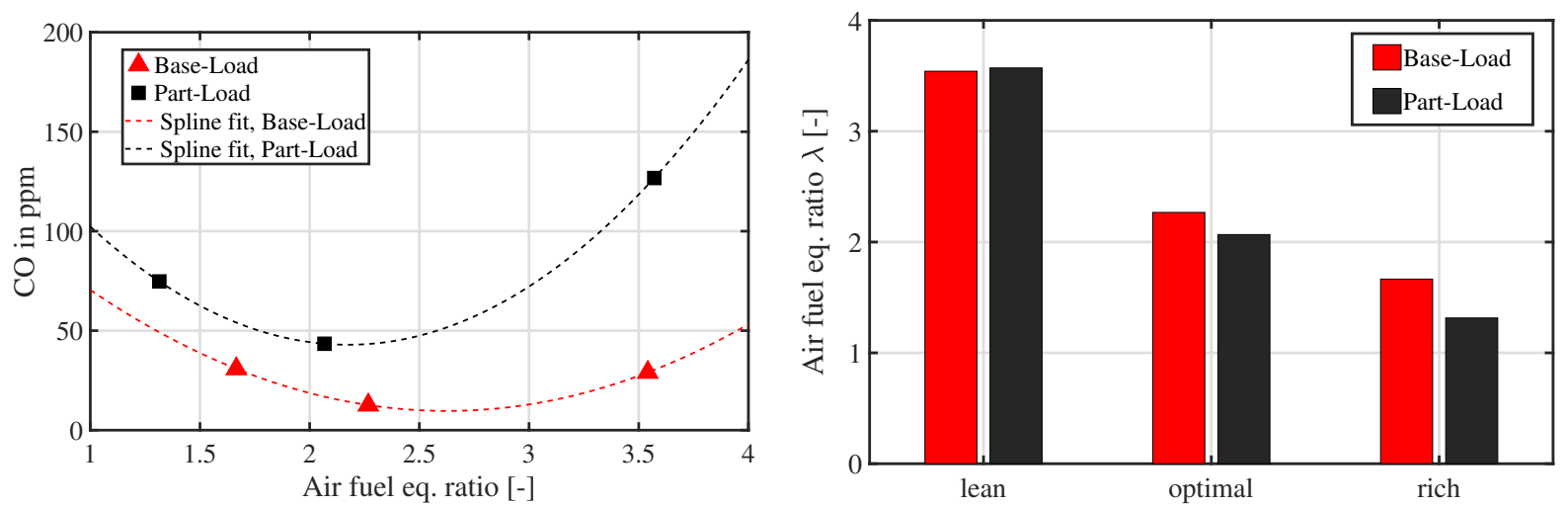

(a) $\mathrm{CO}$ emissions at $15 \%$ oxygen content for base-load and part-load (b) Adiabatic flame temperatures and dT over combustion for base-load operation. and part-load operation.

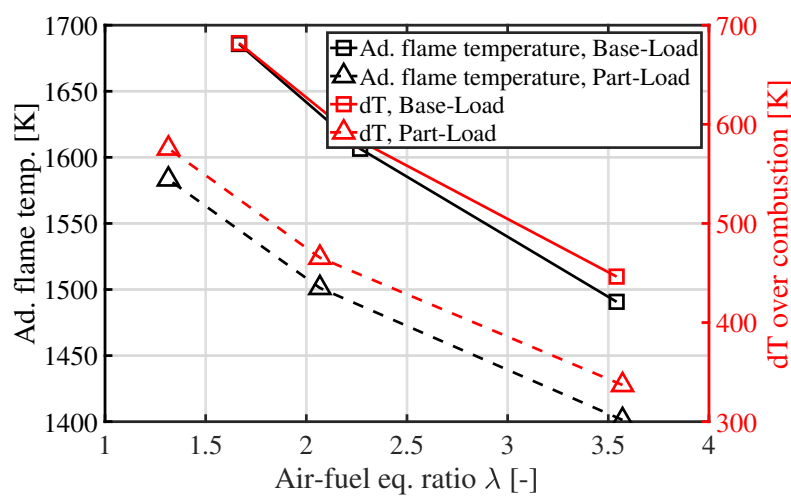

(c) Air fuel ratios for base- and partload operation resulting from com-(d) Averaged characteristic velocities in the burner system for base- and bustor boundary conditions.

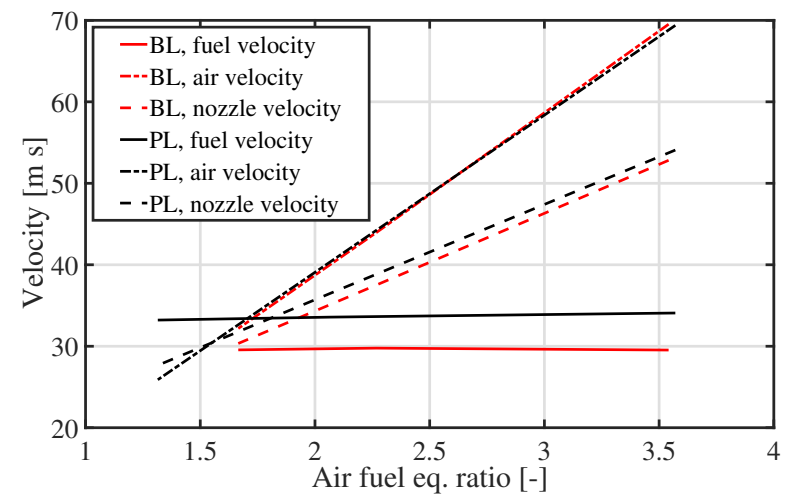

partload operation.

Fig. 4 Global characteristics of the investigated operation conditions of the burner system F20OG.01. 
low. Remarkable are the temperature deltas over combustion, computed without heat-loss effects. In base-load operation, they are in the range of $d T_{\text {Base }} \in[450 \mathrm{~K} ; 700 \mathrm{~K}]$, whereas in the part-load cases, only rather critical values of $d T_{\text {Part }} \in[330 \mathrm{KK} ; 560 \mathrm{~K}]$ are obtained. Therefore, a small amount of natural gas is added for part-load operation [15], in order to ensure combustion stability and a sufficient depiction of the operation range from theoretical computations (Fig. 3). From the very low combustion dTs and low adiabatic flame temperatures, it becomes obvious that heat loss mechanisms have to be necessarily incorporated in the numerical model of this low-calorific application case.

Characteristic average velocities of the burner system are displayed in Fig. 4h. From there it becomes clear that variation of global air fuel ratio is achieved by constant amounts of fuel ("fuel velocity") but a variation of air velocity. Consequently, larger air fuel equivalence ratios mean larger air and nozzle velocities. Due to the fact that nozzle and air velocities are very similar for base- and part-load operation, the two operational regimes are achieved by a variation of fuel amount and composition, where base load operation is characterized by a larger amount of fuel. Details on fuel composition and emulation of SOFC Off-gas can be found in the literature [15].

\section{Measurement Techniques}

Operation cases are characterized by their emission of carbon monoxide and flame shape and position are analyzed via optical non-invasive measurements. Both are briefly described in the following section.

\section{A. OH* Chemiluminescence Optical Measurements}

Under atmospheric conditions, the electronically exited $\mathrm{OH}^{*}$ radical emerges mainly in the reaction zone. Therefore, it is a well suited indicator for the heat release zone. If sampled and averaged over time, it can be used as an indicator of mean flame shape and an approximation of flame lift-off height. Its existence is very short and its decay can be described by the reactions [16, 17]

$$
\mathrm{OH} * \rightleftarrows \mathrm{OH}+\quad \text { radiation }
$$

and

$$
\mathrm{OH} *+\mathrm{M} \rightleftarrows \mathrm{OH}+\mathrm{M},
$$

where Eq. (1) describes the radiation by transition to stable $\mathrm{OH}$ and $\mathrm{M}$ are molecular collision partners. A CCD LaVision camera is used (Imager Pro Plus 2M) with a resolution of 1600x1200 pixels and a LaVision IRO image intensifier. The $\mathrm{OH}^{*}$-signal is detected with a lens resolving wavelengths within 250 - 410nm and multiple optical and transmission band-pass filters are applied to the camera system in order to block background noise and luminescence.

The recorded and line-of-sight integrated volume and the measurement system positioning relative to the combustor are shown in Fig. 5 The integration volume is positioned in a way that two flames are sitting in a row with the line of sight direction.

\section{B. Exhaust Gas Measurements}

Exhaust gas is analyzed after the converging section downstream of the combustion chamber with an ABB process gas analyzer (Advanced Optima process gas analyser AO2000). The air cooled sampling probe is attached to a temperature controlled heated feed hose to the analyzer in order to preserve the original chemical composition. The gas analyzer is able to detect combustion products $\mathrm{H} 2 \mathrm{O}$ and $\mathrm{CO} 2$, oxygen contents and pollutants. In the presented analysis, the focus for pollutant emission lies on carbon-monoxide (CO).

Since the adiabatic flame temperatures are very low in all examined cases, NOx emissions are negligible. CO emissions are shown on a dry basis and normalised to $15 \%$ oxygen. Sampling of data is carried out with a frequency of $2 \mathrm{~Hz}$ over a range of $5 \mathrm{~min}$.

\section{Numerical Setup}

In the following sections, all aspects of numerical modeling used in the present paper are explained. 


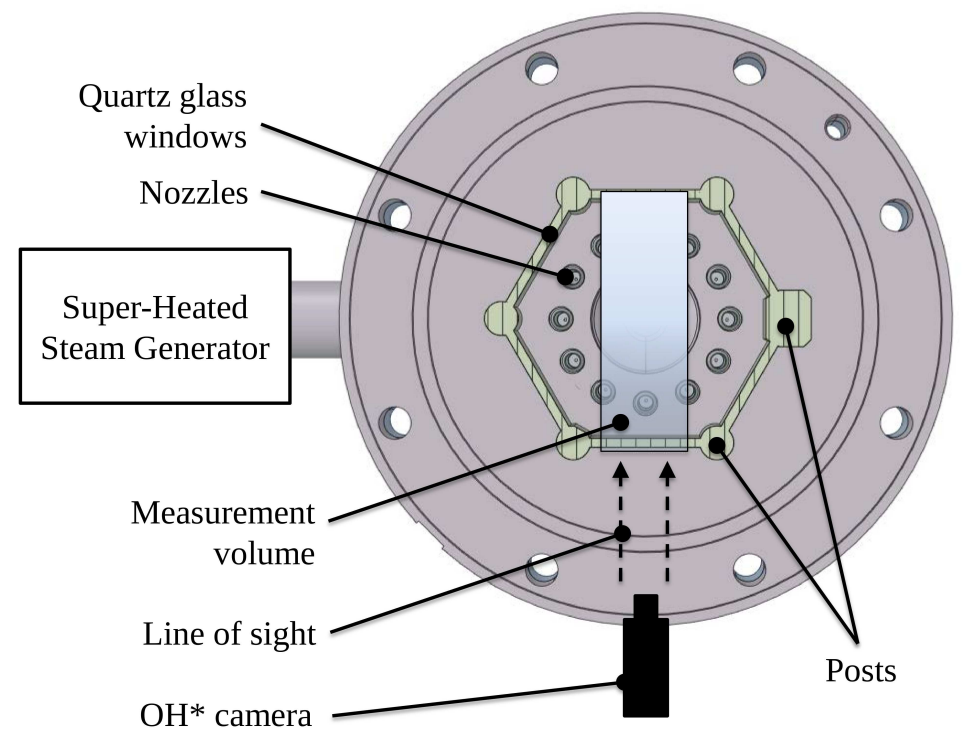

Fig. 5 Top view on the burner with cutting plane through the combustion chamber. $\mathrm{OH}^{*}$ measurement volume indicated.

\section{A. Computational Methods}

Transport equations in their conservative form are solved, yielding conservation of mass, momentum and energy. They are generally given in the form [18]

$$
\int_{V} \frac{\partial \rho \varphi}{\partial t} d V+\oint \rho \varphi \boldsymbol{u} d \boldsymbol{A}=\oint \Gamma_{\varphi} \nabla \varphi d \boldsymbol{A}+\int_{V} S_{\varphi} d V,
$$

where $\rho$ and $\boldsymbol{u}$ are the fluid density and velocity vector. $V$ is the cell volume and $\boldsymbol{A}$ the cell surface area vector. $\Gamma_{\varphi}$ denotes the diffusion coefficient for scalar $\varphi$ and $S_{\varphi}$ is the source of $\varphi$ per unit volume. Additionally, species transport equations are solved and discrete phase particles are tracked in a Lagrangian framework.

The discrete form of Eq. (3) can be written as

$$
\frac{\partial \rho \varphi}{\partial t} V+\sum_{f}^{N_{f}} \rho_{f} \boldsymbol{u}_{f} \varphi_{f} \boldsymbol{A}_{f}=\sum_{f}^{N_{f}} \Gamma_{\varphi} \nabla \varphi_{f} \boldsymbol{A}_{f}+S_{\varphi} V,
$$

with the number of cell faces $N_{f}$ and the face indicator $f$. The expression $\rho_{f} \boldsymbol{u}_{f} \varphi_{f} \boldsymbol{A}_{f}$ denotes the mass flux through the respective face. The first term in Eq. (4) is discretized with temporal schemes in terms an unsteady RANS simulation is performed. Equations of the form as in (4) will be in general nonlinear with respect to $\varphi$. Linearized forms of the discrete equations can be

$$
a_{p} \varphi=\sum_{n b} a_{n b} \varphi_{n b}+b
$$

The subscript $n b$ means neighboring cells and $a$ are the linearized coefficients for the respective $\varphi$. In the present work, spatial discretization is based on first and second order upwind schemes, which are particularly stable during simulation. However, under-relaxation of equations [18] as an additional stabilization mechanism is taken into consideration, leading to partial advancement of solution in each virtual RANS time step,

$$
\frac{a_{p} \varphi}{\alpha}=\sum_{n b} a_{n b} \varphi_{n b}+b+\underbrace{\frac{1-\alpha}{\alpha}}_{1 / C F L} a_{p} \varphi_{o l d},
$$

with the relaxation factor $\alpha$.

\section{B. Grids and Turbulence Modeling}

Grids and the computational domain are depicted in Figs. 7 and 8 Both, a tetrahedral and a polyhedral grid are tested prior to the actual combustion simulations with heat flux, where the polyhedral discretization denotes a 
modeling improvement to the conventional tetrahedral grid. Their statistics and computational turnaround times are listed in Table 1 .

Table 1 Computational statistics, base-load case.

\begin{tabular}{lcccccc}
\hline Grid & Nodes & Elements & Architecture & Comp. Nodes & CPU-h Cold flow & CPU-h Total \\
\hline Tet grid & $6.07 \cdot 10^{6}$ & $20.0 \cdot 10^{6}$ & Intel®Xeon E5-2695 v2 & $5 \cdot 24=120$ & 3,096 & 12,000 \\
Poly grid & $23.8 \cdot 10^{6}$ & $7.9 \cdot 10^{6}$ & Intel®Xeon E5-2695 v2 & $5 \cdot 24=120$ & 1,500 & 7,620 \\
\hline
\end{tabular}

Naturally, polyhedral elements feature a lot more element surfaces compared to tet elements, thus significantly more grid points but less elements are necessary for polyhedral meshing compared to tetrahedral meshing. It becomes obvious from computational turnaround times in Table 1 that the polyhedral grid yields much less computational times compared to the tet grid, which was compared on the same cluster architecture. By comparison of residuals of the two simulations at an exemplary base-load case in Fig. 6, it becomes furthermore evident that a similar quality of convergence is achieved. Stability of the energy equation convergence is much better on the poly grid and oscillation of the approximately converged residual stage are much less pronounced with the poly grid. Therefore, the polyhedral grid is chosen for the simulations presented in this case.

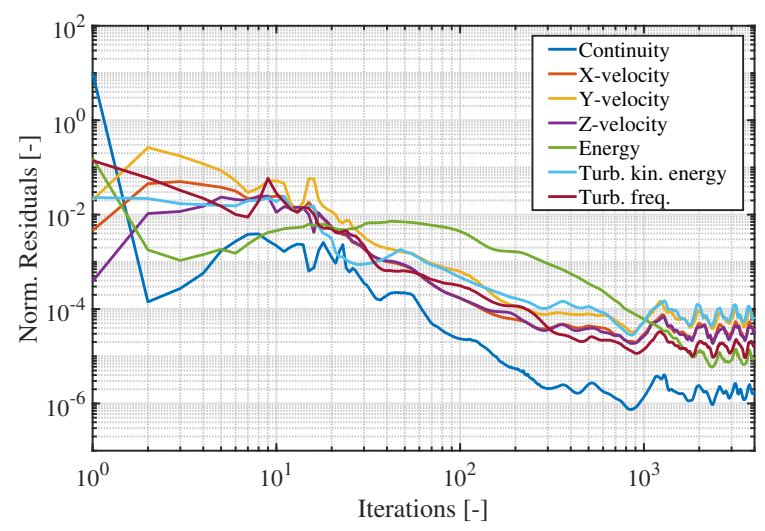

(a) Computation with polyhedral grid as in Fig. 8

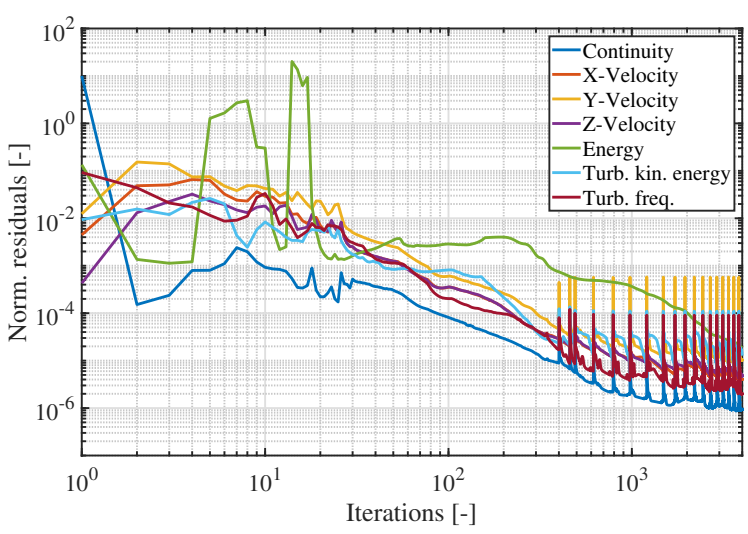

(b) Computation with tetrahedral grid as in Fig. 7

Fig. 6 Normalized residuals for initial cold flow computations for an exemplary base load case. Simulation of 4000 steady state RANS iterations.

In the computational domain, as shown in Figs. 7 and 8 , separate mass flow inlets are present for air and fuel. At the outlet of the domain, the static pressure is set to zero. The combination of mass flow inlets with pressure outlet boundary condition proved to be unconditionally stable for the carried out simulations. Regions of the mixing section between air and fuel as well as the reaction zone in the combustion chamber are significantly refined. Near wall regions are directly resolved with $y^{+} \leq 1$ for the use of a $k \omega$ SST model [19] and a production limiter for the $\omega$ equation is defined.

The quality of near-wall resolution in the numerical simulations is demonstrated in Fig. 9 For the $k \omega$ SST turbulence model to properly function with little inaccuracies in the near wall regions, a value of $y^{+} \leq 1$ is required. This is consequently fulfilled, with $y^{+}$values in the combustion chamber regions are below 0.3 , while $y^{+}$values in the upstream nozzles is still in the order of magnitude of 0.6.

\section{Combustion Modeling}

Reactions are depicted in the numerical simulations with a reduced reaction scheme suitable for syngas combustion from $\mathrm{Li}$ et al. [20]. As a general solution strategy, a cold flow solution is computed first. Chemical reactions are then treated in a simplified way, using the EDM combustion model, where reaction occurrence is mixing dominated. Therefore, a global one-step reaction scheme for hydrogen combustion is set up. Subsequently to EDM combustion the EDC (Eddy Dissipation Concept) from Magnussen [21] is used in order to display multiple reaction time scales 


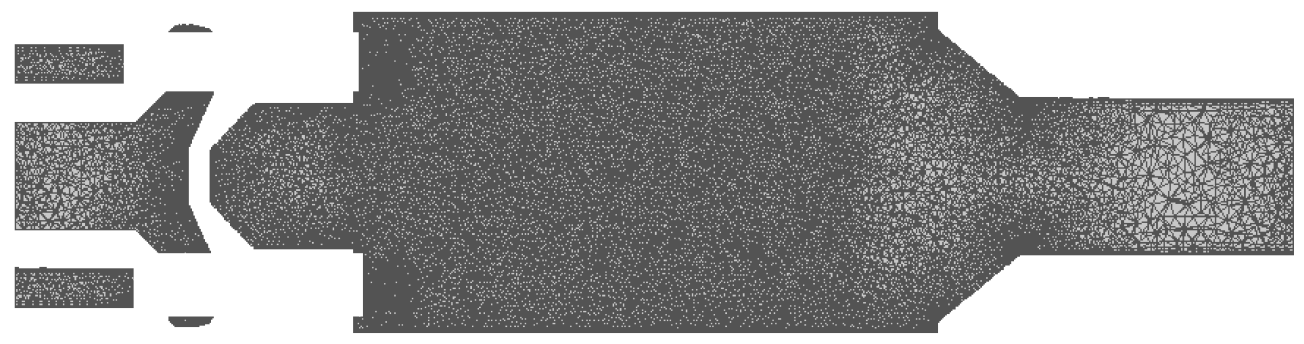

Fig. 7 Tetrahedral computational grid with prism layers (near wall resolution).

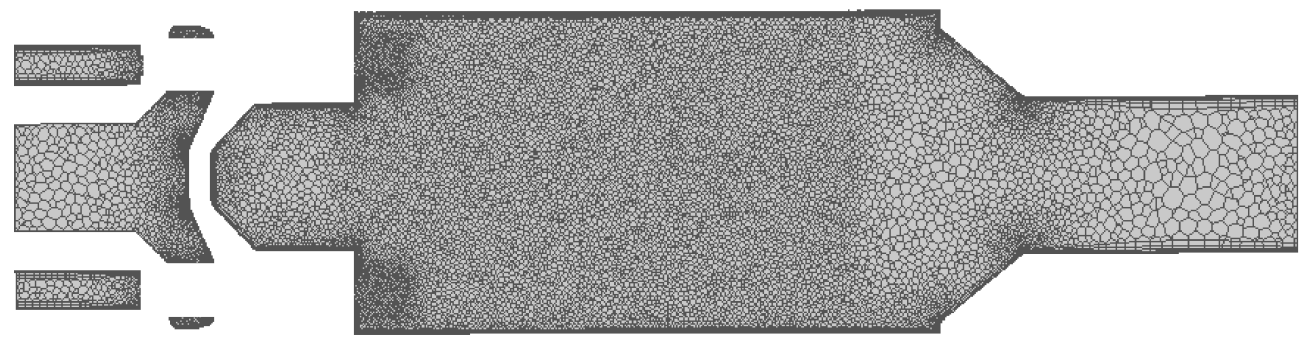

Fig. 8 Polyhedral computational grid with prism layers (near wall resolution).

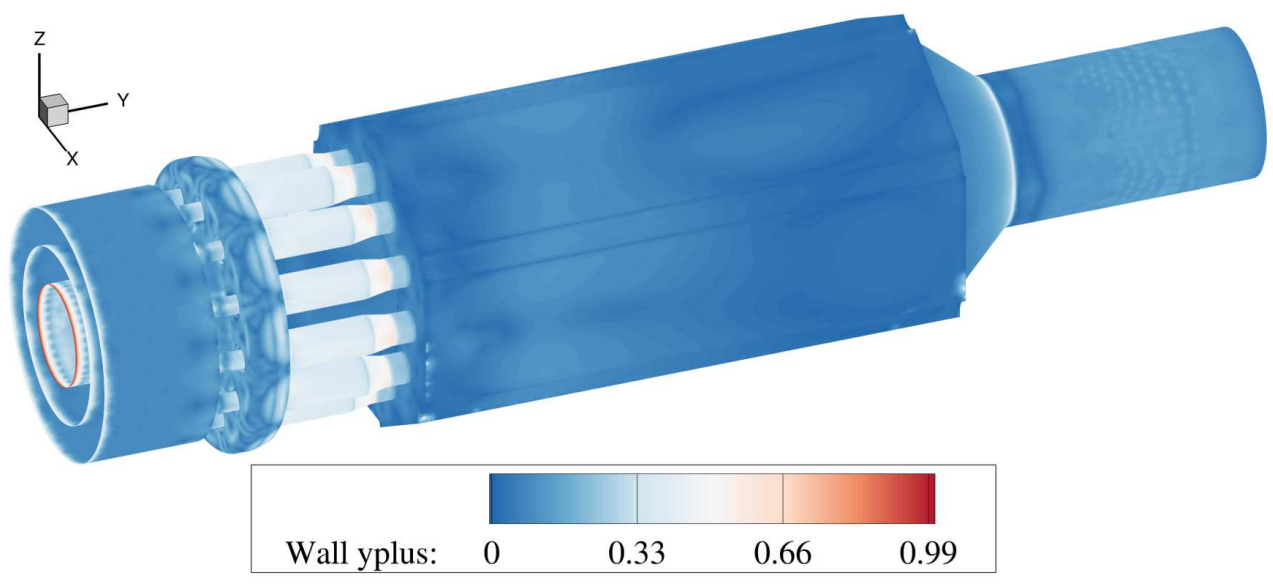

Fig. 9 Distribution of dimensionless $y^{+}$at the combustor walls. 
under partially premixed conditions. The EDC model is particularly suited when parts of the chemical reactions have large time-scales, which is typical for jet-stabilized, FLOX®similar combustion.

In the EDC, reaction is assumed to occur at the small turbulent structures, the so called fine scales and combustion is assumed to take place as a constant pressure reactor. The initial conditions of each reactor are taken as the species and temperature in the respective cell. In each reactor, reactions take place over the chemical time scale $\tau^{*}$, evaluated from

$$
\tau^{*}=0.4082\left(\frac{v}{\epsilon}\right)^{0.5}
$$

Time scales are numerically integrated by using the ISAT algorithm [22]. The source term for species $i$ is then computed from

$$
S_{i}=\frac{\rho\left(\xi^{*}\right)^{2}}{\tau^{*}\left[1-\left(\xi^{*}\right)^{3}\right]}\left(Y_{i}^{*}-Y_{i}\right),
$$

with the fine-scale species mass fractions $Y_{i}^{*}$ and the length scales of the fine-structures $\xi^{*}$, evaluated from $\xi^{*}=$ $2.1377\left(v \epsilon / k^{2}\right)^{0.25}$.

\section{Heat Flux Modeling}

Modeling of heat flux is particularly important in low-calorific combustion. There, and especially in an application with upstream fuel cell as in this study, only little combustible energy is present from the fuel. So heat losses play a significant role in the overall energy balance of the system and have to be taken into account in the numerical model. Radiation however is neglected due to comparably low combustion temperatures.

No information on heat flux exists from experiments. Therefore it has to be estimated in a sensible way. In the present study, this is done by a test case as shown in Fig. 10 .

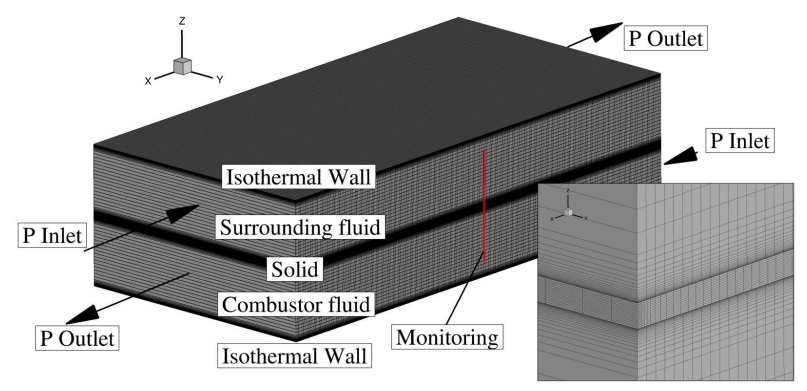

(a) Computational grid and applied boundary conditions.

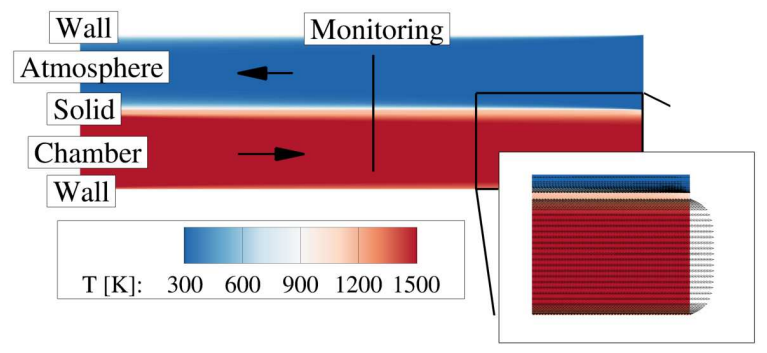

(b) Exemplary results for temperature and velocity distribution.

Fig. 10 Test case for the numerical determination of material dependent heat flux for CFD boundary conditions.

A counter flow configuration is simulated, with a solid medium between the two flows. Solid and fluid are fully coupled and therefore conjugated heat transfer is enabled. One fluid denotes the combustion chamber regime, where a composition of combustion products and appropriate temperatures and flow velocities are applied. Those values are taken from preceding adiabatic simulations of the combustor and the temperature on the combustor side is close to the respective adiabatic flame temperature, as presented in Fig. 4b. The outer fluid stream, called surrounding fluid or atmosphere in Fig. 10 is modeled according to surroundings of the combustion chamber, which are subject to air drain by an exhaust fan.

The computational grid directly accounts for near wall resolution and a sufficient resolution of the solid in heat transfer main direction, which is orthogonal to the two fluid flow streams. A $k \omega$-SST turbulence model is used and pressure boundary conditions for the fluid streams. In y-direction, symmetry boundary conditions are applied, while the domain is enclosed by isothermal walls in z-direction, where either the adiabatic flame temperature or ambient air temperature is set.

In the application case, heat transfer through several different materials has to be considered. Quartz glass for the optically permeable walls, heat-resistant steel of the posts and the combustion chamber front plate, and high quality steel in the upstream section of the combustion chamber. Results for the different solid materials and a case accounting 
for a larger solid material, are shown in Fig. 11. Depicted are temperature profiles in z-direction. Heat flux values are evaluated with

$$
\dot{Q}=a \cdot \frac{\Delta T}{\Delta z}=a \cdot \frac{T_{W}-T_{d z}}{z_{W}-z_{d z}} .
$$

$a$ is the heat conductivity of the fluid on the combustion chamber side, and is estimated to $a \approx 0.054 \mathrm{~W} /(\mathrm{m} \cdot \mathrm{K})$. Quantities with index $W$ are evaluated directly at the wall, whereas $d z$ denotes the wall normal height of the first cell at the wall.

From the results in Fig. 11 it becomes obvious that the heat flux is highly dependent on the solid material. Quartz glass for example has a much higher thermal resistance than the high temperature steel or stainless steel. Furthermore the heat flux is highly dependent on the peak temperature level of the combustor side, which influences the slope of the temperature curves close to the combustor walls.

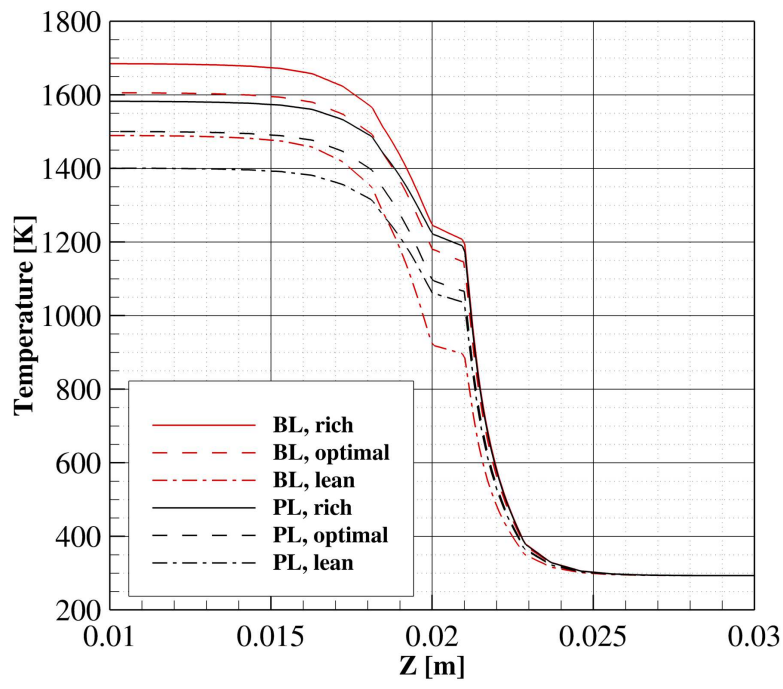

(a) Combustion chamber glass wall transitions.

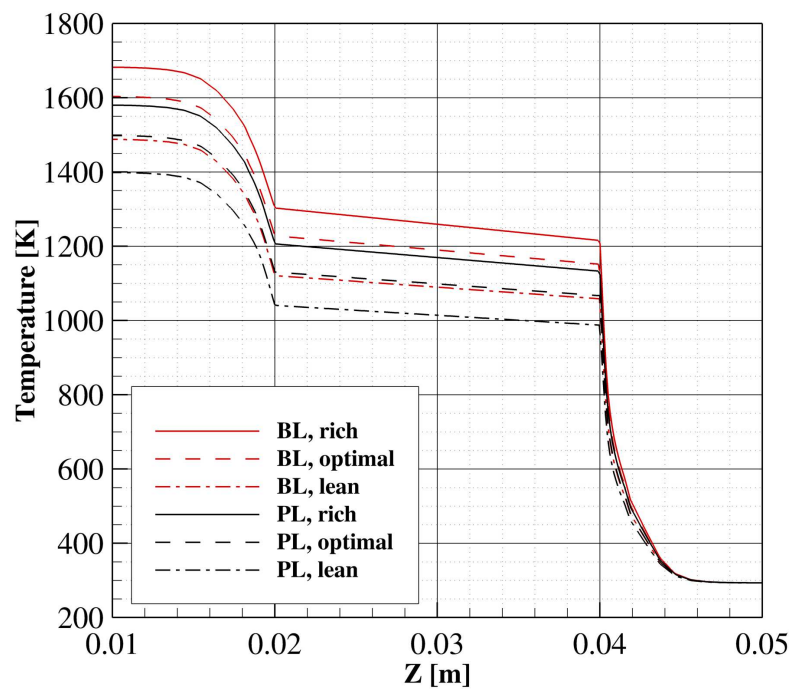

(c) Combustion chamber front plate steel transitions.

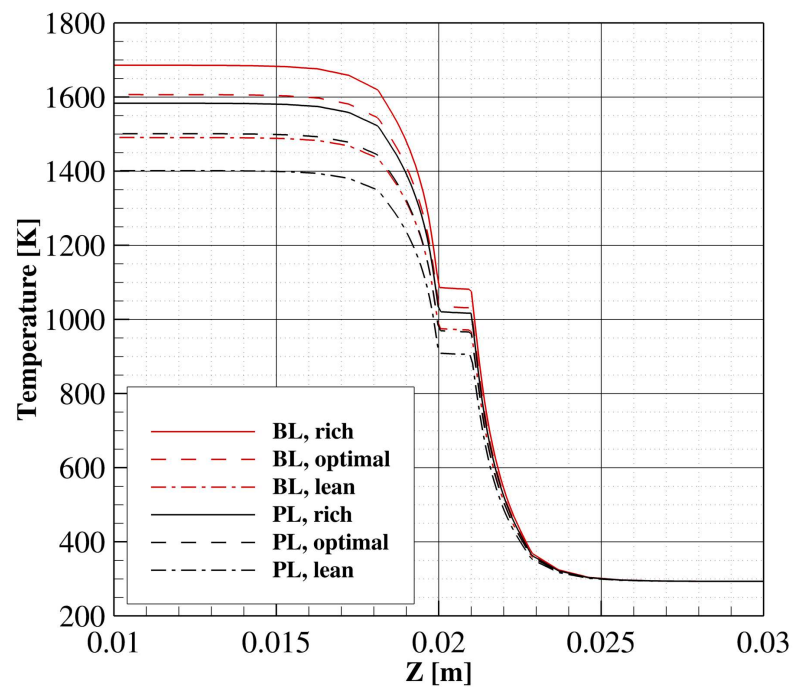

(b) Combustion chamber hasteloy steel transitions.

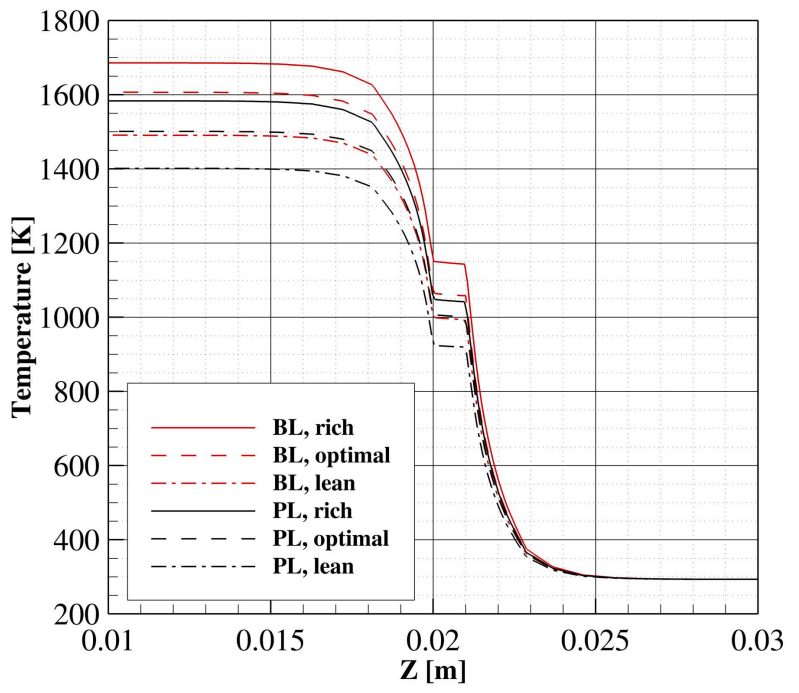

(d) Upstream section steel transitions.

Fig. 11 Study of temperature profiles in wall normal direction for the effect of conjugated heat transfer in a counter flow test case.

The heat flux values as applied in the application case are shown in Fig. 12. The model is simplified in a way that 
constant values of heat flux are applied to certain regions of the combustor. However, the effects of different materials with different thermal properties are taken into account, which significantly affects combustion in the chamber itself and the pre-heating of fuel and air. Largest heat flux values are applied in the upstream and downstream sections of the combustor, where high temperature resistant steel is used in the experiments. The combustor front plate values are taken from Fig. 11, , where a thicker solid plate is modeled. Combustion chamber side walls are impinged with values from Fig. 11 for the quartz glass, whereas the side posts holding the glass windows are not distinguished, in order to reduce complexity of the model.

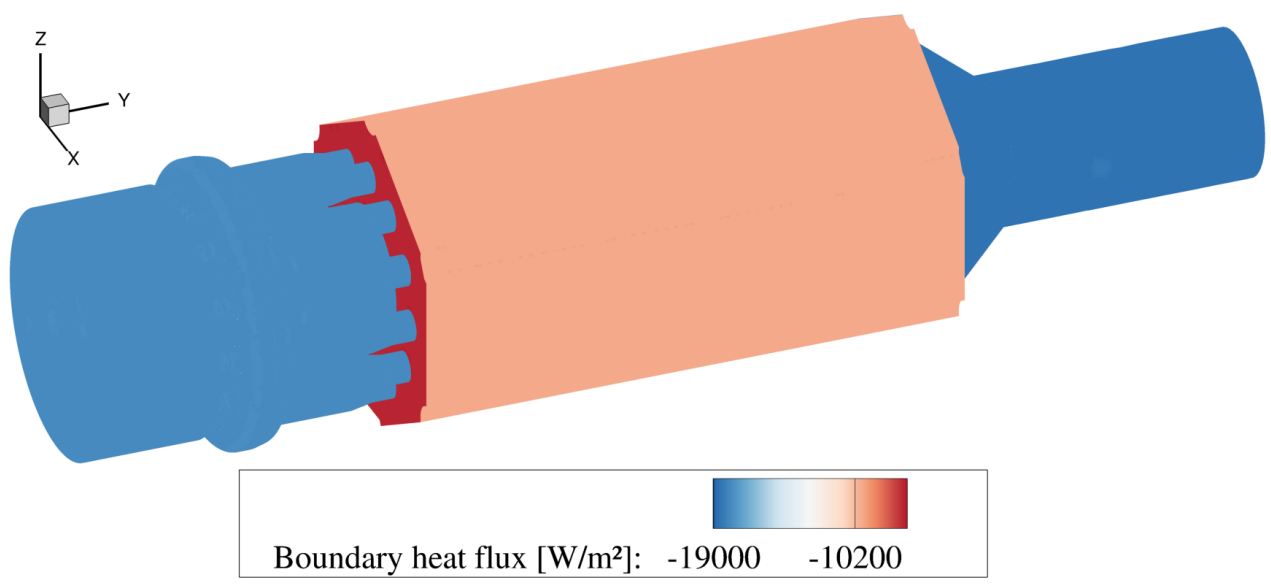

Fig. 12 Heat flux boundary condition sections in the combustor computational domain with the respective values obtained from a counter-stream test case.

\section{Results and Validation with Experimental Data}

In this section, the numerical results are compared with experimental data. First, numerical simulations of statistical $\mathrm{OH}^{*}$ concentration are compared to experimental $\mathrm{OH}^{*}$ measurements. If the numerical model can be validated in terms of flame shape and position, it is deduced that flow field and temperature characteristics can aid the experimental data set with valid results for velocity distribution and combustion characteristics.

\section{A. General Flow Field and Flame Properties}

For a detailed discussion of later results, it is advantageous to introduce general properties of jet-stabilized combustion first by looking at exemplary base load case properties from numerical simulations. This is shown in Figs. 13 and 14

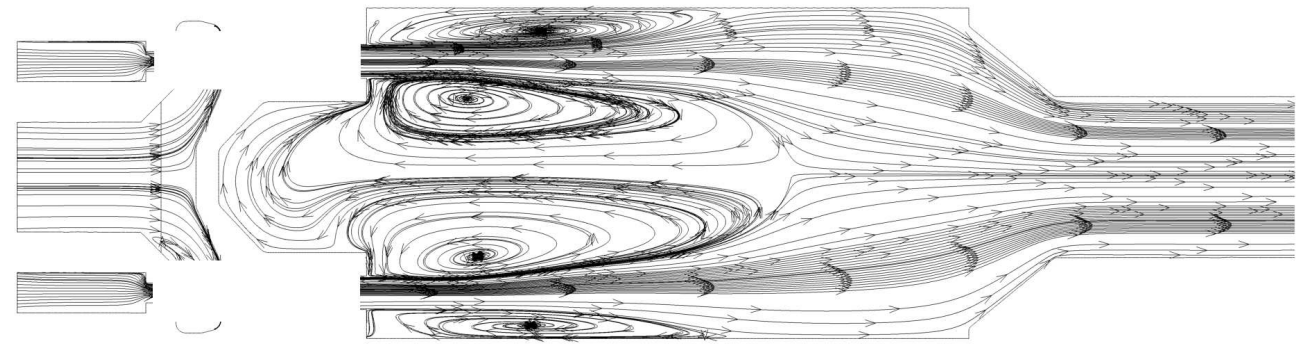

Fig. 13 Average streamlines in a combustor mid-plane from CFD RANS base-load simulations.

Characteristic for jet-stabilized, encased combustion is the formation of high velocity jets, issuing into the combustion chamber from circumferentially aligned nozzles, where air and fuel is mixed after a co-flow fuel induction. By those jets being induced in axial direction, large recirculation zones form. This can be seen in Fig. 13 There are 
mainly outer recirculation zones between combustion chamber walls and reaction zones and inner recirculation zones with large spatial extensions. They contribute to stability of combustion by transporting hot combustion products back to the flame roots. Downstream of the recirculation zones there is a stagnation point, followed by highly accelerated flow due to the converging burner geometry towards the exhaust duct.

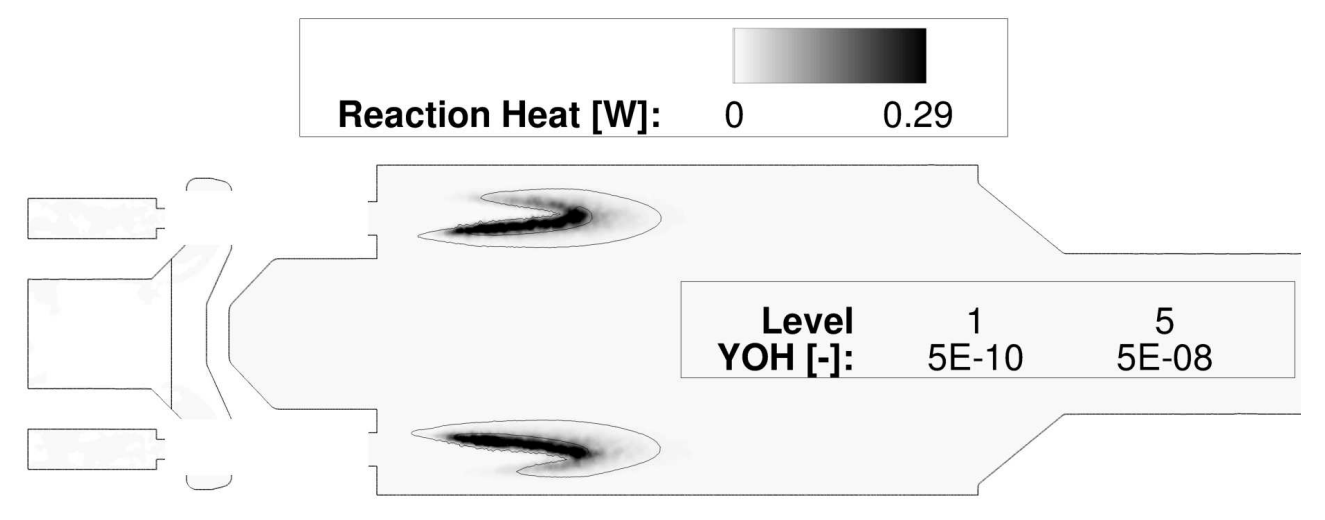

Fig. 14 Overlay of mean reaction heat from combustion and approximated $\mathrm{OH}^{*}$ concentration in a combustor mid-plane.

Properties of combustion are displayed exemplary in Fig. 14 Jet-stabilized flames usually feature a horseshoe similar shape, which is indicated by the heat of reaction. In the present, partially premixed combustion regime, relatively thick reaction zones with large spatial extensions form. Presence of a large variety of chemical time-scales and significant turbulence chemistry interaction is assumed. Estimation of the $\mathrm{OH}$ radical from numerical simulations in Fig. 14] shows similar characteristics as the reaction heat but is slightly offset further downstream and spatially much more distributed.

\section{B. Reaction Zone and Flame Extensions}

Comparison of experimentally and numerically obtained flame shapes, extensions and positions are displayed in Figs. 15 and 16 Numerical simulations are evaluated in a way that they suit the $\mathrm{OH}^{*}$ measurement techniques. Therefore, a control volume which equals the experimental line-of-sight field is defined and simulation results are first interpolated onto the new domain and then integrated in line-of-sight direction.

Consequently, this means that results in Figs. 15] and 16] do not cover three discrete flames but six, with perfect optical alignment between two, respectively.

In the base load case in Fig. 15, several properties of the flames can be deduced from experimental data. First of all, the burner produces discrete flames that vary only slightly in terms of lift-off height with varying air flow rate. Please note that the amount of fuel induced into the system stays constant for the respective base and part load cases. In base load operation, flames are more elongated when approaching the richer regime, which seems counter-intuitive at first. This can be explained with several aspects. In the lean regime, jet air velocity is highest. This in turn leads to stronger inner recirculation and therefore an increased re-transportation of hot combustion products to the reaction zone. Therefore, reactivity is highest in the lean regime, leading to more compact flames. Another aspect contributing to increased reactivity in the lean case is that pre-heating of air is higher than pre-heating of the fuel stream. Increased mass flow rates of air in the lean case therefore results in hotter air-fuel mixtures.

In the numerical simulation results, this trend is partially captured as well. Here, averaged reaction zones tend to be more compact in axial direction but the lower reactivity towards rich conditions shows with increased flame lift off heights. Increase in lift-off height which does not show in the experiments is assumed in general underestimation of turbulence degrees in RANS modeling, leading to worse mixing of fuel and air compared to experiments. The employed EDC combustion model is based on local reactors, which also take into consideration local mixing induced by turbulence. The overall flame shape is however nicely captured by the numerical simulations. Especially in the lean regime, the match of experiment and numerical simulation is excellent. This is remarkable especially since only low-fidelity models are used in the CFD.

In the part load cases, as shown in Fig. 16 the same observations as for the base load case hold. In part load, 


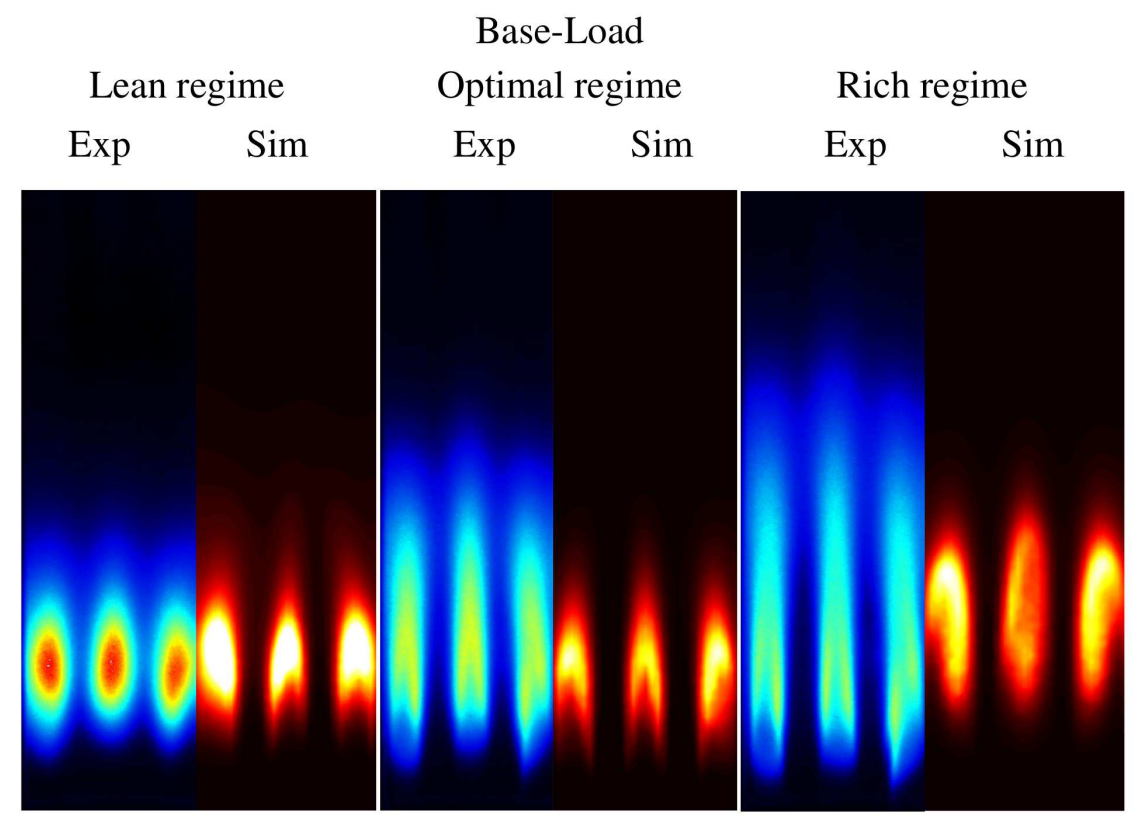

Fig. 15 Comparison of experimental and numerically obtained $\mathrm{OH}^{*}$ distribution in the combustion chamber indicating average flame shape and position. Base-load operation.

\section{Part-Load}

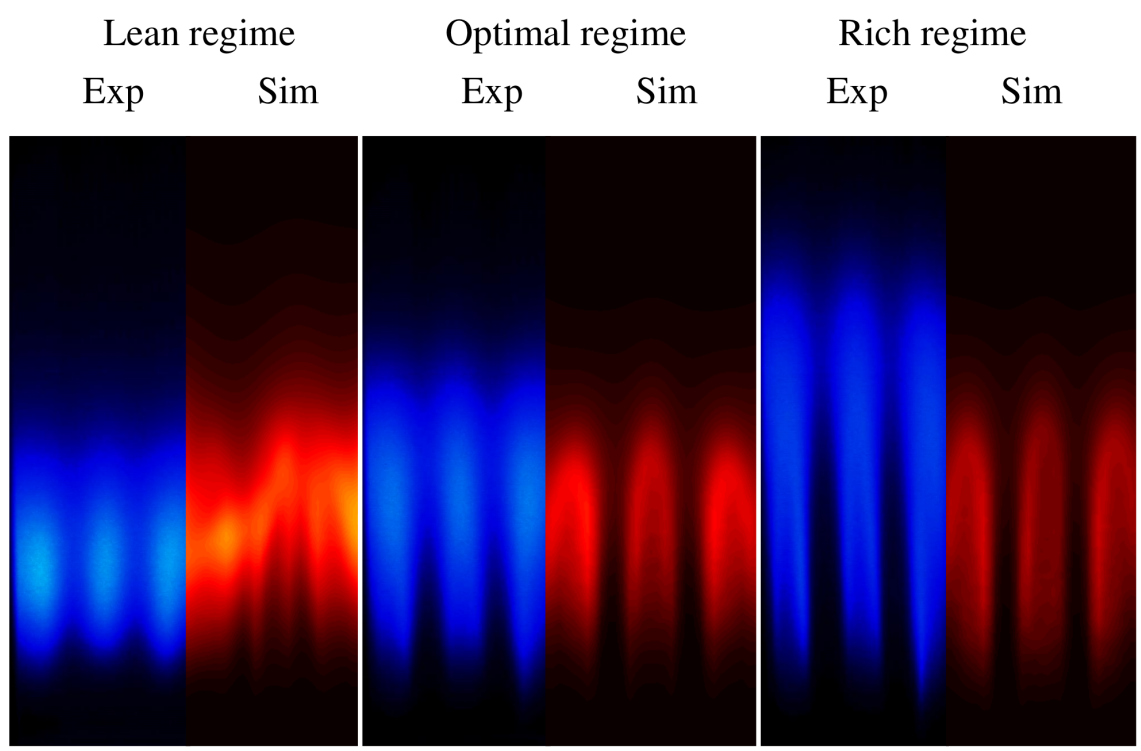

Fig. 16 Comparison of experimental and numerically obtained $\mathrm{OH}^{*}$ distribution in the combustion chamber indicating average flame shape and position. Part-load operation. 
calorific values of the fuel are even less than in the base load case (see Fig. 4 4 ). As mentioned previously, methane is added to the fuel in order to enhance combustion stability. At the same time, air nozzle velocities are almost identical (see Fig. 4 d). As a consequence, the reaction zone is far more stretched than in the base load case and carried off further downstream. This effect comes along with more unsteadiness in the reaction regime and the interaction of the flames with larger turbulent structures. This inevitably leads to increased pollutant formation of CO, compared to the base load case, as becomes evident from see Fig. 4h.

In part load operation, numerical simulation results show about the same good quality of reproduction of experimental results as in the base load cases. It can be concluded that the employed chemical reaction scheme is not only suitable for syngas combustion at low calorific conditions but is also able to depict reactions with methane addition. Towards richer conditions, simulations to not predict the more elongated reaction zones, however the trends are still captured well. Note that especially part load conditions are hard to capture accurately in the numerical simulations, since they are apparently close to blow-off as is shown by experimental data.

\section{Flow Field and Temperature Distribution}

As shown in the preceding section, numerical simulations nicely reproduce experimentally obtained averaged reaction zone positions and spatial extensions. They are therefore used to complement the experimental data set with information on flow field and temperature distribution in the combustion chamber.

Axial velocity fields for the different regimes and cases are depicted on a mid-plane section in Fig. 17 The general characteristics of the flow field as discussed in a preceding section are nicely reflected in the results. Those are distinct jets issuing into the combustion chamber, strong and spatially large recirculation zones especially around the inner combustor main flow axis and acceleration of the flow towards the combustion system exhaust duct.

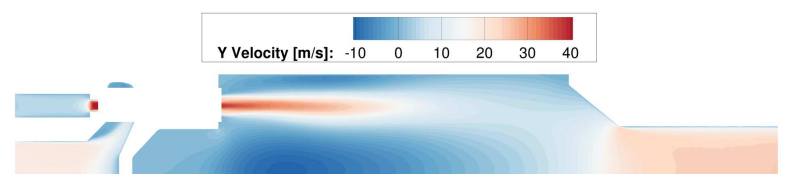

(a) Base-load, Rich regime, $\lambda=1.67$.

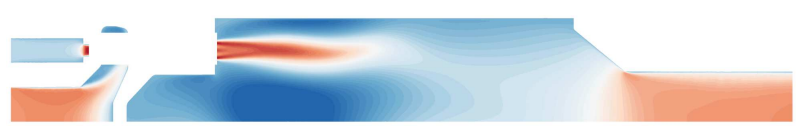

(c) Base-load, Optimal regime, $\lambda=2.27$.

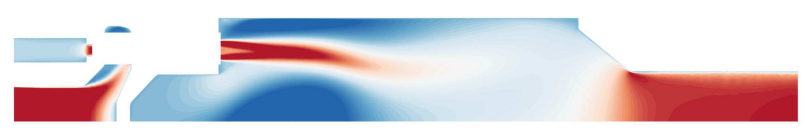

(e) Base-load, Lean regime, $\lambda=3.54$.

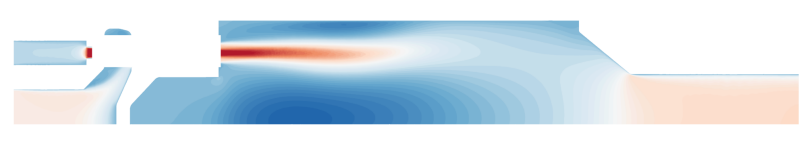

(b) Part-load, Rich regime, $\lambda=1.31$.

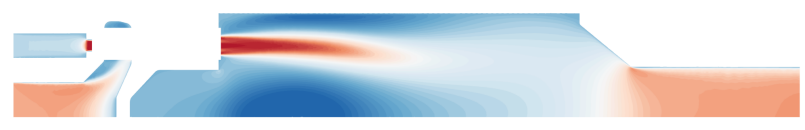

(d) Part-load, Optimal regime, $\lambda=2.07$.

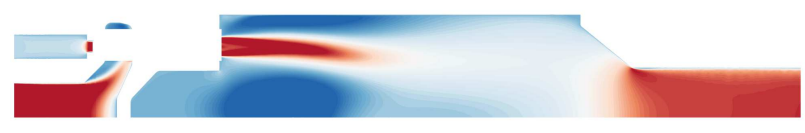

(f) Part-load, Lean regime, $\lambda=3.57$.

Fig. 17 CFD RANS mid-plane section contours of axial velocity. Left: Base-load, right: part-load.

All velocity values in Fig 17 are scaled to the values of the base load case in the rich regime at $\lambda=1.67$. In the rich regime of base and part load, jets are straight and not deflected by certain flow features. This changes for the optimum cases and is most pronounced in the lean regimes. Jet velocities steadily increase from rich to lean regimes in both part load and base load operation and therefore the inner recirculation zones become stronger but also more compact. This leads to low pressure regions around the burner axis, which drags the jets towards the burner axis. Consequently, recirculation zones close to the walls gain more prominence.

On the fuel induction side, more fuel is induced in the rich regime, compared to the lean regime. This affects the core region of the jets when entering the combustion chamber. Towards the leaner regimes, the outer air streams grow stronger compared to the inner fuel jet stream, leading to different flow patterns at the end of the air fuel mixing section, which can be observed in Fig. 17 right after the blended out regions of the nozzles.

Temperature distributions of the simulated cases for base and part load are displayed in Fig. 18, again normalized to the values of the base load case in the rich regime. Notable are the low combustion temperatures, reaching from about $1450 \mathrm{~K}$ in the rich base load case to around $1250 \mathrm{~K}$ in the lean part load regime. The accountancy for heat loss 


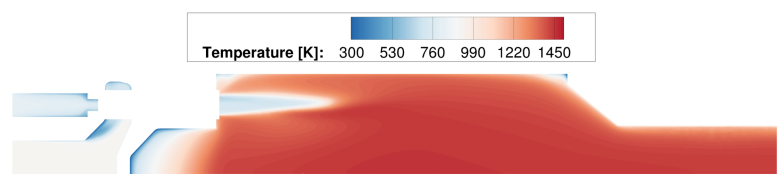

(a) Base-load, Rich regime, $\lambda=1.67$.

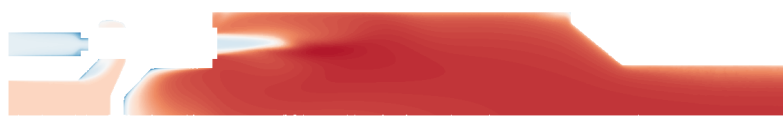

(c) Base-load, Optimal regime, $\lambda=2.27$.

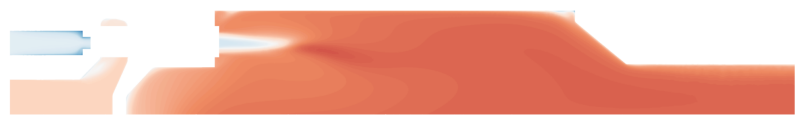

(e) Base-load, Lean regime, $\lambda=3.54$.

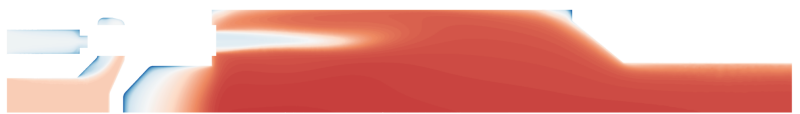

(b) Part-load, Rich regime, $\lambda=1.31$.

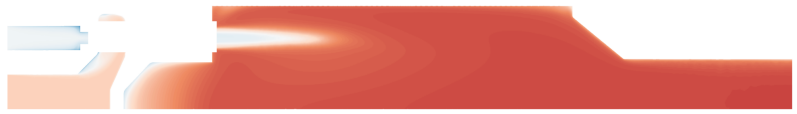

(d) Part-load, Optimal regime, $\lambda=2.07$.

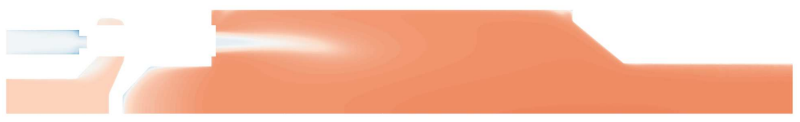

(f) Part-load, Lean regime, $\lambda=3.57$.

Fig. 18 CFD RANS mid-plane section contours of temperature. Left: Base-load, right: part-load.

effects can be seen for decreasing temperatures at the combustion chamber and upstream walls. Temperature gradients at the walls are rather sharp in the combustion chamber itself, due to higher flow velocities compared to upstream and recirculation sections. Especially for the base load cases, it can be detected that the wall and therefrom emerging heat loss effects affect chemical reactions in the combustion chambers. It appears that peak temperature spots are produced predominantly at the inner shear layer of the jets, facing the inner recirculation zones, whereas temperatures are distinctly lower in the outer recirculation zones.

From the numerical results in Figs. 17 and 18 it can be concluded that the CFD RANS simulations are highly consistent in predicting changes in operation load parameters in this complex, low-calorific application case and are therefore highly suitable as a diagnostics tool aiding experimental data.

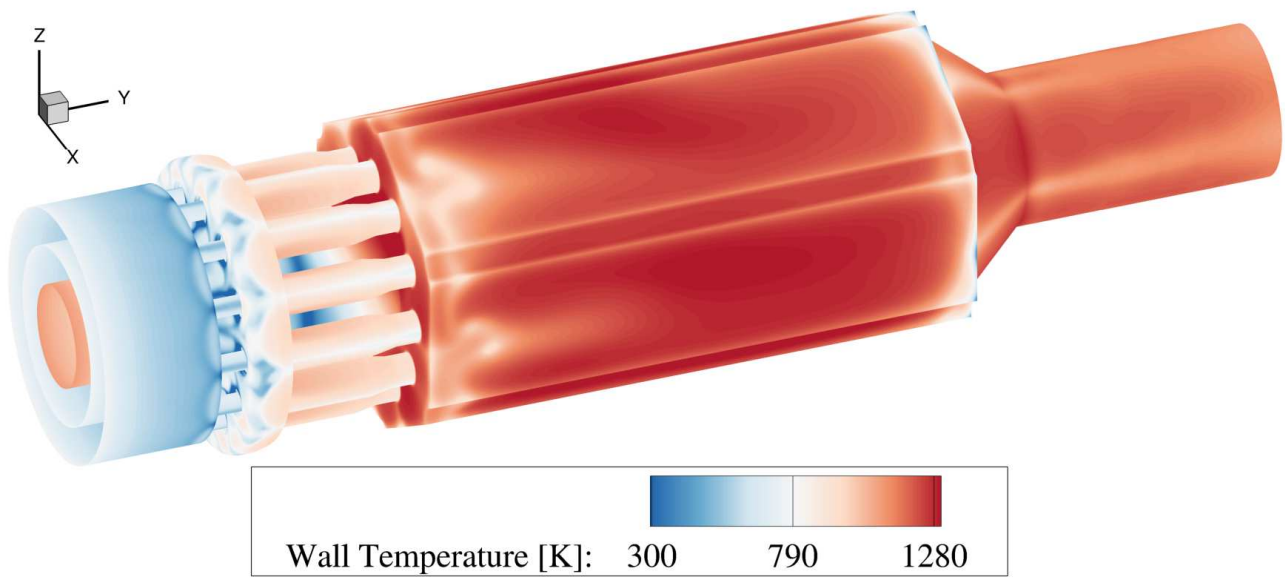

Fig. 19 Distribution of wall temperatures from a CFD base-load case simulation.

Another aspect of validation between experimental and numerical data is the distribution of wall temperatures, which should be captured in experiments at least for certain reference conditions, in order to be able to validate heat flux assumptions in the CFD. An exemplary distribution of combustor wall temperatures are shown in Fig. 19 Apparently the most heated parts are the combustion chamber front plate and the combustion chamber walls, as well as the combustor exhaust duct. Another aspect that shows in Fig. 19 is the different degree of preheating of air and fuel. Lowest overall wall temperatures occur close to the fuel nozzles. 


\section{Summary and Conclusions}

A jet-stabilized combustion system was experimentally and numerically investigated. Its operational field was constructed in the context of hybrid power plant employment with upstream solid oxide fuel cell (SOFC), which makes it a low-calorific off-gas application. The fuel cell was emulated with an upstream heated stream generator. Combustion with very low heating values made it necessary to use methane addition to the fuel (SOFC off-gas), at least in part load operation, in order to ensure combustion stability.

Base and part load operation was investigated, with a lean, an optimum and a rich case, respectively, deduced from reference $\mathrm{CO}$ emissions characteristics. On the experimental side, optical measurements were conducted capturing $\mathrm{OH}^{*}$ radicals in the reaction zones and exhaust gas measurements, since combustion systems operated in energy applications are required to run with low emissions.

The main focus of this work lied in the establishment of a numerical model of the burner system and its validation with experimental data. As a consequence of successful validation with $\mathrm{OH}^{*}$ concentrations the numerical simulations were further used as diagnosis tool in order to aid experimental data with flow field and temperature information.

A model accounting for turbulence, combustion and heat loss modeling was established, which showed very good agreement with experimental data. It was demonstrated that the carried out simulations are capable of successfully reproducing low-calorific, jet-stabilized combustion with the accurate incorporation of heat loss effects and fuel dilution with methane. Therefore, in future works, the numerical model can be employed for substitution of costly experimental measurements for the characterization of further operation points.

\section{Acknowledgments}

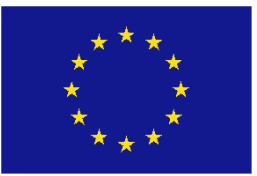

This project has received funding from the European Union's Horizon 2020 research and innovation programme under grant agreement No 641073 (www.bio-hypp.eu).

\section{References}

[1] Hohloch, M., Huber, A., and Aigner, M., "Analysis of Operational Strategies of a SOFC/MGT Hybrid Power Plant," Proceedings of the ASME Turbo Expo, Charlotte, NC, USA, 2017. GT2017-65013.

[2] Bücheler, S., Huber, A., and Aigner, M., "Development of a Jet-Stabilized Combustion System for the use of Low-Caloric SOFC Off-Gas," Proceedings of the ASME Turbo Expo, Charlotte, NC, USA, 2017. GT2017-64447.

[3] Hermann, F., Palsson, J., and Mauss, F., "Combustor Design Analysis for SOFC Off-gases," 5th Solid Oxide Fuel Cell Forum, Lucerne, Switzerland, 2002.

[4] Loukou, A., Voss, S., Mendes, M., Raimondi, A., and Trimis, D., "Parametric experimental investigation of a small scale packed bed reactor for Thermal Partial Oxidation," 4th European Combustion Meeting, Vienna, Austria, 2009.

[5] Voss, S., Mendes, M., Pereira, J., and Trimis, D., "Comparison of Experimental and Numerical Results of Ultra-Lean H2/CO Combustion within Inert Porous Media," 4th European Combustion Meeting, Vienna, Austria, 2009.

[6] Wünning, J., and Wünning, J., "Flameless oxidation to reduce thermal NO-formation," Progress in Energy and Combustion Science, Vol. 23, No. 1, 1997, pp. 81-94. doi:10.1016/S0360-1285(97)00006-3.

[7] Cavaliere, A., and Joannon, M., "Mild Combustion," Progress in Energy and Combustion Science, Vol. 30, No. 4, 2004, pp. 329-366. doi:10.1016/j.pecs.2004.02.003.

[8] Flamme, M., "Low NOx Combustion Technologies for High Temperature Applications," Energy conversion management, Vol. 42, 2001, pp. 1919-1935. doi:10.1016/S0196-8904(01)00051-6.

[9] Lückerath, R., Meier, W., and Aigner, M., "FLOX® Combustion at High Pressure With Different Fuel Compositions," Journal of Engineering for Gas Turbines and Power, Vol. 130, No. 1, 2008. doi:10.1115/1.2749280.

[10] Flamme, M., "New combustion systems for gas turbines (NGT),” Applied Thermal Engineering, Vol. 24, 2004, pp. 1551-1559. doi:10.1016/j.applthermaleng.2003.10.024.

[11] Lammel, O., Stöhr, M., Kutne, P., Dem, C., Meier, W., and Aigner, M., "Experimental Analysis of Confined Jet Flames by Laser Measurement Techniques," Proceedings of the ASME Turbo Expo, Vancouver, Canada, 2011. GT2011-45111. 
[12] Rödiger, T., Lammel, O., Aigner, M., Beck, C., and Krebs, W., "Part-Load Operation of a Piloted FLOX® Combustion System," Journal of Engineering for Gas Turbines and Power, Vol. 135, No. 3, 2013, pp. 031503-01. doi:10.1115/1.4007754.

[13] Zanger, J., Monz, T., and Aigner, M., "Experimental Investigation of the Influence of Combustor Cooling on the Characteristics of a FLOX®-Based Micro Gas Turbine Combustor,” Progress in Gas Turbine Performance, 2013, pp. 165-184. doi: $10.5772 / 54405$.

[14] Monz, T., Stöhr, M., O’Loughlin, W., Zanger, J., Hohloch, M., and Aigner, M., "Experimental characterization of a swirl stabilized MGT combustor," Proceedings of the ASME Turbo Expo, Montreal, Canada, 2015. GT2015-42387.

[15] Lingstädt, T., Grimm, F., Krummrein, T., Bücheler, S., and Aigner, M., "Experimental Investigation of a SOFC Off-Gas Combustor for Hybrid Power Plant Usage with Low Heating Values Realised by Natural Gas Addition," Proceedings of the GPPS Forum 2018, Global Power and Propulsion Society, Montreal, Canada, 2018. GPPS-2018-0052.

[16] Dandy, D., and Vosen, S., "Numerical and Experimental Studies of Hydroxyl Radical Chemiluminescence in Methane-Air Flames," Combustion Science and Technology, Vol. 19, 1992, pp. 131-150. doi:10.1080/00102209208951816.

[17] Lee, J., and Santavicca, D., "Experimental Diagnostics for the Study of Combustion Instabilities in Lean Premixed Combustor," Journal of Propulsion and Power, Vol. 19, 2003, pp. 735-750. doi:10.2514/2.6191.

[18] ANSYS, I., ANSYS Fluent Theory Guide, 2017. Release 18.2.

[19] Menter, F., “Two-Equation Eddy-Viscosity Turbulence Models for Engineering Applications,” AIAA Journal, Vol. 32, No. 8, 1994, pp. 1598-1605. Https://doi.org/10.2514/3.12149.

[20] Li, J., Zhao, Z., Kazakov, A., Chaos, M., and Dryer, F., "A Comprehensive Kinetic Mechanism for CO, CH2O, and CH3OH Combustion," Int. J. Chem. Kinet., Vol. 39, 2007, pp. 109-136. doi:10.1002/kin.20218.

[21] Magnussen, B., "On the Structure of Turbulence and a Generalized Eddy Dissipation Concept for Chemical Reaction in Turbulent Flow," Nineteenth AIAA Meeting, St. Louis, 1981.

[22] Pope, S., "Computationally efficient implementation of combustion chemistry using in-situ adaptive tabulation," Combustion Theory and Modeling, Vol. 1, 1997, pp. 41-63. Https://doi.org/10.1080/713665229. 